\title{
Study on the Deep Development of the Tourist Area of Sanya from the Perspective of Global Tourism
}

\author{
Yuan Qi ${ }^{1, a}$ \\ ${ }^{1}$ University of Sanya, Sanya, Hainan, 572000 \\ a email
}

Keywords: Sanya, Tourist Area, Deep Development

\begin{abstract}
This paper focuses on the development and protection of tourism resources in Sanya. Its main contents are six parts: international tourism island, resource status, resource development, resource protection, system security and resource industry. The international tourism island expatiates on the connotation and significance of Hainan international tourism island, the overall requirements, the main tasks and the status and role of Sanya in the construction of international tourism island. This is the realistic background of Sanya tourism resources investigation and evaluation, development and protection. The current situation of the resources of Sanya expounded the classification, situation, characteristics and quality of tourism resources in Sanya, which is the basic basis for the development and protection of tourism resources in Sanya. Resource development part of the Sanya tourism resources development of the spatial layout, timing arrangements, the basic way and Sanya tourism product innovation, which is the main content of tourism resources in Sanya. The protection of tourism resources, the protection of tourism resources, the protection of tourism environment and the protection mode of tourism resources are the main contents of the protection of tourism resources in Sanya.
\end{abstract}

\section{Introduction}

Construction of international tourism island, Hainan is facing a new historical mission. Sinclair and Stabler have summarized the new trend of tourism development in the 21st century as follows: tourism will always maintain a good momentum of development, the unique advantages of tourism itself will be more and more people's attention, the tourism industry will grow, tourism consumer products (M Then Sinclair and Mike Stable, 1997), the tourism industry has an irreplaceable and important role. Hainan's strategic positioning of international tourism island is: first, China's tourism reform and innovation pilot area; second, world-class island leisure resort destination; third, the national ecological civilization construction demonstration area; fourth, the international economy Cooperation and cultural exchange an important platform; Fifth, the South China Sea resources development and service base; Sixth, the national tropical modern agricultural base. This shows that the construction of international tourism island in Hainan has been formally incorporated into the national development strategy, Hainan in China's overall pattern of reform and development in the status and role of another upgrade.

Construction of international tourism island, Hainan is the development of ideas to further improve. At the beginning of the special economic zones, Hainan has put forward some development ideas and made many useful explorations. After the "one province and two" development ideas gradually become the mainstream, the construction of new industrial province, to create a modern tropical agricultural production base and tropical tourism and leisure resort to become the province's efforts to achieve the goal. Construction of international tourism island explicitly requires the development of service economy, open economy, eco-economy, the formation of tourism as a leader, modern service industry-oriented characteristics of the economic structure, the construction of a beautiful ecological environment, unique cultural charm, social civilization and peaceful opening Island, Green Island, the island of civilization, the island of harmony, which is the development of ideas to further enhance and improve. 


\section{Construction of International Tourism Island Connotation}

Based on Hainan's unique resource advantages. Hainan's most abundant and unique resource is nothing else, that is, tropical tourism resources. There are numerous tropical coastal landscape: the ends of the earth, Yalong Bay, the East China Sea, the East China Sea, Sanya Bay, Begonia Bay, Shimei Bay, Hong Bay, Sun Moon Bay, Guilin Yang, West Coast, pawn Bay and so on. There are also very precious landscape scenery: Wuzhishan, Diaolingshan, Jianfengling, Bawangling, Qixiangling, Tongguling, Baishiling, Dongshanling, Mao Gongshan, Wanquan River, Xinglong Hot Springs, South Hot Springs, Guantang Hot Springs, Blue Hot springs and so on. In addition, there are a large number of natural resources and human resources to be exploited. All of which constitute a unique domestic, international first-class sightseeing, leisure and vacation conditions. Ignore the most abundant, the most unique resources to talk about the development and construction of Hainan, not blindly also look.

Adapted to the requirements of ecological civilization construction. The 17th National Congress of the Communist Party of China put forward the requirement of building an ecological civilization, which is epoch-making. Ecological civilization construction is not just planting trees and grass, not just clean, can not make it too narrow understanding. In this paper, "ecological civilization" contains three kinds of deep reflection: the first is the "industrial civilization" reflection - in the industrial era, people greatly conquered nature, but soon was the natural retaliation, resource depletion , Environmental degradation and other issues have endanger the survival of mankind. People gradually realize that mankind must live in harmony with nature, only in harmony with nature in the process of going to the future. The second is a reflection of the philosophy of struggle. For a long time, we have not examined and summed up the thinking of the revolutionary Party, but have continued to use the thinking of the revolutionary party to do the ruling party. Philosophy "of the generalization, so with the" class struggle "of the expansion, the impact of the relationship between people has become very complex, moral integrity suffered severe damage. The third is a reflection of sound personality - for a long time, we do not pay attention to physical health and mental health, or only concerned about the health of the health is not concerned about, at some point, and even certainly morbid psychology, identify the residual psychological, and crown to "Revolutionary", "struggle" and so on. In this context, it is entirely correct and timely to propose a harmonious society. "Harmony" should contain three meanings: harmony between man and nature, harmony between people, their own harmony, the sum of the three is the integrity of ecological civilization. Hainan International Tourism Island has six major positioning, they are: China's tourism reform and innovation of the pilot area, a world-class island leisure tourism destination, the national ecological civilization demonstration area, an important platform for international economic cooperation and cultural exchanges, South China Sea resources development and service base, the national tropical modern agricultural base. In the six positioning, "ecological civilization construction demonstration area" is the basic positioning. The basic requirements of this positioning are: adhere to the ecological province, the environment priority, in the development of protection, in the development of protection, promote resource-saving and environment-friendly society, to explore the harmonious development of man and nature of civilization, The socialist harmonious society of the road to success, to provide a national ecological civilization construction of the real example. Obviously, Hainan has the most conditions, the most advantage to play this role, the most conditional, the most advantageous in this area to be successful.

\section{Analysis of Sanya 's Tourism Resources}

Sanya tourism resources is not only extremely rich, and unique. Compared with similar tourist sites at home and abroad, it has the following salient features:

Sanya is China's only tropical coastal city, which makes it in many cities in China has an irreplaceable position. Here long summer without winter, sunny, humidity changes are relatively stable. Here the average annual sunshine number 2563 hours, the annual average temperature of 25.6 degrees Celsius, the annual sunny days in more than 300 days, the average annual rainfall of 
$1279 \mathrm{~mm}$, the minimum monthly temperature of 10 degrees Celsius. It has a typical tropical marine monsoon climate, and it has a very unique comprehensive climate resources, making it one of China's most famous shelter, known as "the world's exports of sun and air" The

Sanya City, rich in tourism resources, as mentioned earlier, it has $100 \%$ of the class, as a significant size is small, the population was significantly less prefecture-level cities, Sanya City, the type of tourism resources are more complete, the number of more The obvious features. At the same time, Sanya City, the density of tourism resources is also large, as mentioned above, Sanya City, tourism resources in the number of monomers owned by the general, which has more than 80 elements of the "middle class" should have : Weather, water scenery, construction facilities. If you want to answer the simplest way to Sanya's tourism resources, you can say: "only" + "first", the former said that Sanya is China's only tropical coastal city, which is said that it has high quality Water scenery tourism resources called the first in the country, it is in this sense, people say Sanya "is not Hawaii, is better than Hawaii"!

Very high quality and grade. Compared with similar domestic and foreign coastal cities, Sanya has the top 3S resources. It is the world's first-class beach; it is the world's first-class coast; it can be with the world any beach type Travel compared to no less.

Of course, Sanya tourism resources also have their relative disadvantage, mainly as follows: on the whole, the natural tourism resources are rich, humanistic tourism resources are relatively weak. From the natural tourism resources, the coastal landscape is very rich, the other landscape is relatively weak. From the perspective of cultural tourism resources, although there are a number of high-level tourism resources, such as the International Wedding Festival, Miss World Competition, drop hole, but they are either shallow history, foundation is not deep, or content is flat, attractive is not strong The Taken together, compared with similar tourist areas at home and abroad, Sanya tourism resources, the prominent disadvantage is the natural resources and human resources, a strong and weak, can not be coordinated. At the same time, their adaptability to the tourists in the warm winter is better, in the hot summer is poor.

\section{Basic Mode of Tourism Resources Development in Sanya}

In other words, the Daxing civilized tourism development should be cautious attitude. Sanya tourism development has been a considerable scale, with a good foundation, the future focus should not be the amount of expansion, but the quality of the upgrade. Adjust the structure and enhance the grade, is the future of Sanya tourism resources development focus. In other words, Sanya should focus on solving the problem of more tourism products and less holiday products, to solve the relatively advanced housing industry and shopping, restaurants, bars, tea and entertainment it is relatively lagging behind the problem. In this premise, highlighting the Begonia Bay, the two rivers and three nights night project construction issues.

That is to say, on the improvement of civilized transformation should be a positive attitude. Scenic areas (points) of the aging, backward tourism facilities, should be more positive attitude to transformation and upgrading. The difference between "ascension" and "construction" is that the former focuses on qualitative improvement, and the latter focuses on the expansion of quantity. In a certain sense, for the development of tourism resources in the industry, "promotion" is more than "construction" For example, Nanshan tourist area, the ends of the earth tourist area, the East China Sea tourist area, the size of the cave tourism area, Luhuitou tourist area, their development has been more mature, therefore, "construction" type of development should be basically stopped, instead This "promotion" should be expressed as: the transformation of individual old and backward facilities, but the scope and intensity of the transformation should not be too large, and the transformation should be to protect the sea, the beach , Coastal vegetation and historical relics as an important principle of tourism area Xiaoxing civil engineering construction of its layout, height, size, color and other colors should be coordinated with the overall environment.

That is, not comprehensive civil use should be more and better. In foreign countries, Oxford University tour, Cambridge University tour has long been popular, people in this kind of tourism can get a fruitful harvest. In the country, Peking University campus tour, Tsinghua University tour 
also began to rise, people interested in such tourism no less than any other kind of tourism. Oxford, Cambridge, Peking University, Tsinghua, etc., almost no need to make any "development" to achieve the purpose. Sanya in the development of tourism resources in the process, it is clear that this article should be done, the so-called "civil" and do the romantic, such as the development of "Sanya at sea", "tropical rain forest experience", "Phoenix Island view" and so on. The means of tourism resource protection usually include legal means, government-led, business and social participation. Legal means to emphasize through the relevant legislation, law, judicial work, so that tourism resources are effectively protected; government-led refers to the government needs to protect the protection of tourism resources, rational planning, effective supervision and positive as. Business management refers to the tourism enterprises should correctly handle the relationship between the state, society and enterprises, reasonably determine the carrying capacity of tourist areas, and collect and deal with tourism waste in time. Social participation is to mobilize the whole society to participate in tourism resources management, to strengthen the protection of tourism resources, education, the establishment of tourism resources protection funds and so on.

\section{Conclusion}

Based on the study of the tourism industry in Sanya City, this paper discusses the development of tourism resources in Sanya under the background of building an international tourism island in Hainan, and then discusses the development of tourism resources in Sanya. And the protection of the problem, the scientific answer to the status of Sanya tourism resources characteristics, rational development, effective protection, the construction of related systems and tourism resources industry development and a series of issues for Sanya as the construction of international tourism island vanguard provides a theoretical basis and intellectual support.

\section{Acknowledgement}

This paper is stage result of 2018 Hainan Province, colleges and universities in general science research project hold by associate professor Zhang Hongshuang "South China Sea Island ecological footprint of uninhabited resources".

\section{References}

[1] Shen Shiwei, Violier Philippe. Research Methods and Evolution of Tourism Resources in French Geography [J]. Journal of Beijing Second Foreign Language Institute, 2010 (05)

[2] Yu Yang, Wang Erda. Study on the Evaluation of Recreational Value of Tourism Resources at Home and Abroad [J]. East China Economic Management, 2009 (09)

[3] Fan Dingxiang, Fu Lihua. Study on the Market Operation of Tourism Resources Capitalization [J]. Journal of Hunan University of Technology (Social Science Edition), 2009 (01)

[4] Zhu Hong, Chen Xiaoliang. Study on Spatial Distribution Structure of China's Grade A Tourism Scenic Spot [J] .Acta Geographical Science, 2008 (05)

[5] Huang Xiang. Transition planning across the major administrative regions should break through the "tourism planning general rules" [J]. Journal of Tourism, 2008 (08)

[6] Ma Yaofeng, Li Junyi. Study on the Cognitive Model of Tourists' Geographical Space [J] .Journal of Remote Sensing, 2008 (02) 